\title{
Pengaruh Selip Terhadap Kerusakan Tanah Pada Kegiatan Pengangkutan Kayu Pinus Merkusi
}

\author{
Yuniawati; Sona Suhartana \\ Peneliti pada Pusat Penelitian dan Pengembangan Keteknikan Kehutanan dan Pengolahan Hasil \\ Hutan, Jl. Gunung Batu No. 5 Bogor 16610 \\ Email: yunia_las@yahoo.co.id
}

\begin{abstract}
Abstrak
Kegiatan pengangkutan kayu sering terkendala oleh selip yang terjadi, terutama pada kondisi jalan tanah angkutan kayu yang licin. Perlu adanya upaya untuk mengurangi selip tersebut, dengan menggunakan alat bantu rangkaian besi kotak. Tujuan tulisan adalah untuk mengetahui pengaruh selip terhadap kerusakan tanah yang terjadi, dengan menggunakan alat bantu maupun tidak menggunakan alat bantu. Hasil penelitian menunjukkan bahwa terdapat hubungan antara selip dengan kerusakan tanah pada jalan angkutan kayu. Semakin besar selip maka kerusakan tanah yang terjadi juga akan semakin besar. Kerusakan tanah tersebut dapat menghambat kelancaran distribusi kayu ke industri pengolahan kayu. Upaya untuk mengurangi selip dapat dilakukan dengan menggunakan alat bantu, sehingga pengurangan terjadinya selip dapat dicapai sebesar $89,19 \%$.
\end{abstract}

Kata Kunci : Jalan licin, kerusakan tanah, pengangkutan kayu, selip

\section{PENDAHULUAN}

Kayu memiliki manfaat apabila telah dikeluarkan dari dalam hutan. Kegiatan pengangkutan kayu berperan penting guna mengeluarkan semua kayu dari areal hutan (petak tebang) ke luar hutan (industri atau langsung konsumen). Penggunaan truk umum digunakan pada kegiatan pengangkutan kayu di hutan tanaman lahan kering.

Truk adalah alat yang khusus digunakan sebagai alat angkut karena kemampuannya yang dapat bergerak cepat, luwes, kapasitas angkut besar dan dapat digunakan untuk mengangkut bahan materi apa saja (Wedhanto, 2009) Truk menggunakan ban karet sebagai alat traksinya. Ban traksi dari karet memiliki traksi yang baik tetapi memiliki kelemahan yaitu cepat aus (Radite, et al., 2008).

Penggunaan truk sebagai alat angkut kayu terkadang mengalami selip. Selip merupakan pengurangan kecepatan maju kendaraan. Semakin besar selip yang terjadi maka akan semakin kecil tenaga yang tersedia untuk menarik maju kendaraan. Jadi untuk mengetahui berapa besar gaya tarik yang dapat dihasilkan kendaraan perlu diketahui koefisien traksi.

Hasil penelitian Harseno et al., (2007) juga menyebutkan bahwa apabila salah satu roda kehilangan traksi (gaya gesek) maka roda yang berlawanan tidak bisa berputar. Padahal truk sering berjalan pada jalan-jalan yang tidak rata, jalan berpasir, jalan lumpur, jalan licin atau yang lainnya. Dengan 
kondisi jalan yang demikian, maka sering sekali salah satu roda mobil tersebut kehilangah traksi (gaya gesek) sehingga akan mengalami selip. Apabila salah satu roda selip maka roda yang berlawanan tidak bisa berputar, sehingga mobil tersebut tidak bisa berjalan. Jadi agar mobil bisa berjalan kembali maka roda yang selip harus diberi traksi, sehingga tenaga dari mesin akan tersalur ke kedua roda.

Kondisi selip menyebabkan satu roda berputar terus menerus sampai menggerus tanah dibawahnya. Gerusan tanah dari ban membentuk alur atau parit sepanjang kondisi ban selip. Alur atau parit tersebut dapat merusak agregat tanah. Sangat membahayakan bagi keselamatan truk angkutan. Untuk mengurangi selip tersebut maka diperlukan alat bantu. Tulisan ini bertujuan untuk mengetahui pengaruh selip terhadap kerusakan tanah yang terjadi, dengan menggunakan alat bantu maupun tidak menggunakan alat bantu.

\section{METODE PENELITIAN}

\subsection{Lokasi dan Waktu Penelitian}

Pelaksanaan penelitian dilakukan pada tahun 2013. KPH Sukabumi terletak di Kabupaten Sukabumi Jawa Barat dan ditetapkan berdasarkan SK Menhut no 195 tahun 2003. Secara keseluruhan luas KPH Sukabumi adalah 78.125,18 ha yang terdiri dari hutan produksi seluas 18.462,53 ha, hutan produksi terbatas seluas 39.261,21 ha, hutan konservasi dengan luas 20.401,44 ha dan hutan lindung tidak ada. Hutan produksi dan produksi terbatas dengan luas 58.385,26 ha terdiri dari kelas perusahaan jati seluas $11.853,18$ ha dan kelas perusahaan rimba seluas $46.532,08$ ha.

Secara geografi terletak diantara $6^{\circ} 57^{\prime} \mathrm{LS}$ dan $7^{\circ} 20^{\prime \prime}$ LS serta $106^{\circ} 41^{\prime} \mathrm{BT}$ dan $107^{\circ} 00^{\prime} \mathrm{BT}$, sedangkan batas wilayah adalah sebelah utara Kabupaten Bogor, sebelah timur Kabupaten Cianjur, sebelah selatan Samudera Indonesia dan sebelah barat Propinsi Banten (Kabupaten Lebak). Kondisi iklim di KPH Sukabumi sesuai kriteria Schmidt dan Fergusson bertipe hujan B yaitu seluas 58.159,08 ha dan bertipe A seluas 537,61 ha. Tipe hujan A tersebar diseluruh BKPH yang ada sedangkan tipe hujan B terdapat di BKPH Cikawung. Rata-rata curah hujan berkisar antara 28.600 $\mathrm{mm}$ - $33.900 \mathrm{~mm} / \mathrm{tahun}$. Jenis tanah yang ada dominan latosol coklat kemerahan, latosol coklat kekuningan dan padsolik merah kuning. 


\subsection{Bahan dan Alat penelitian}

Bahan yang digunakan adalah truk pengangkut kayu, alat yang digunakan adalah alat bantu berupa rangkaian besi kotak, meteran, stopwatch, sekop dan alat tulis.

\subsection{Prosedur Penelitian}

\subsubsection{Merancang dan membuat alat bantu logging}

Gambar alat bantu untuk mengurangi selip dari besi kotak yang dirangkai disajikan pada Gambar 1.

\subsubsection{Uji coba alat bantu}

Tahapannya adalah :

a. Menetapkan petak ukur terpilih dilakukan dengan cara purposif,yang mewakili kondisi licin

b. Menetapkan perlakuan terdiri dari yaitu : faktor penggunaan alat bantu rangkaian besi berbentuk kotak dan faktor tidak menggunakan alat bantu.

c. Melaksanakan pengamatan dan pengukuran selip pada roda truk.

1) Memberi tanda pada ban truk menggunakan cat putih, pada saat truk berjalan dan tanda tersebut menyentuh tanah atau alat bantu dihitung jumlah putaran rodanya.

2) Melaksanakan pengukuran selip pada ban truk yang melalui alat bantu dan tidak menggunakan alat bantu dengan cara mengukur selisih jarak tempuh truk tanpa muatan kayu dengan truk bermuatan kayu pada jumlah putaran roda yang sama.

3) Melaksanakan pencatatan jarak tempuh, volume kayu, waktu tempuh dan jumlah perputaran roda.

4) Melaksanakan pengamatan tekstur tanah langsung di lapangan dengan memirit tanah menggunakan jari dan merasakan halus kasarnya partikel tanah.

Pengukuran parameter meliputi selip roda dan kerusakan tanah. Cara pengukuran parameter dijelaskan seperti berikut ini.

a. Selip roda truk: mencatat selisih jarak tempuh truk tanpa muatan kayu dengan yang bermuatan kayu pada kondisi roda truk melalui alat bantu dan tidak melalui alat bantu. 
b. Kerusakan tanah : mengukur kedalaman tanah yang terbentuk akibat selip pada sisi kiri atau kanan ban truk.

Pengumpulan data sekunder meliputi: keadaan umum lapangan, keadaan umum perusahaan dan data penunjang lainnya yang dikutip dari perusahaan dan wawancara dengan karyawan.

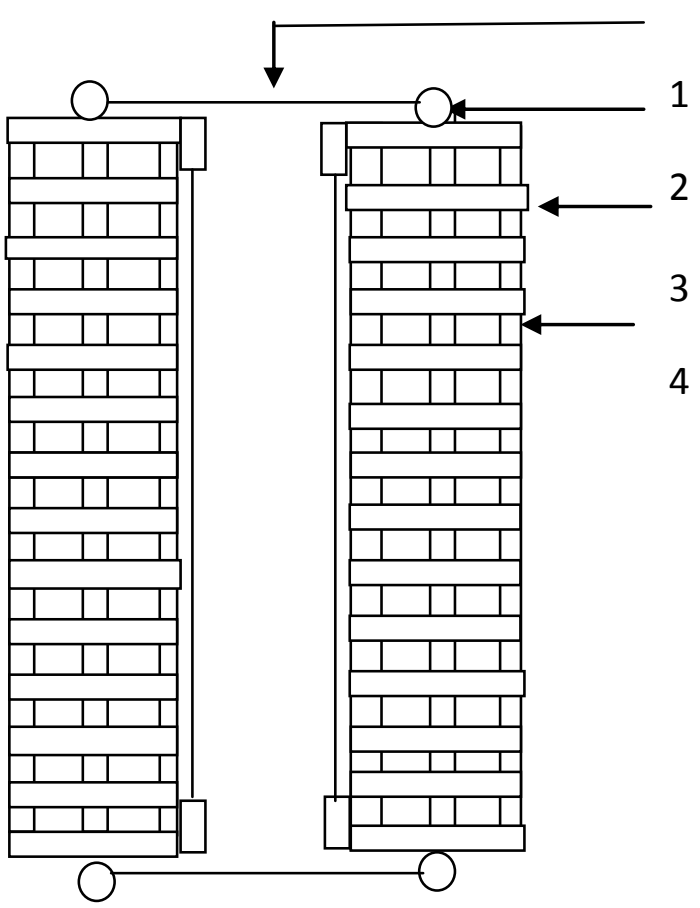

Sumber: Kementerian Kehutanan (2014)

Keterangan gambar:

1. Kawat penghubung diameter $12 \mathrm{~mm}$ panjang $110 \mathrm{~cm}$

2. Cincin penghubung diameter $4 \mathrm{~cm}$ dari besi behel berdiameter $1 \mathrm{~cm} \mathrm{x} 4 \mathrm{~cm} \mathrm{x} 2 \mathrm{~mm}$.

3. Jari-jari alat bantu dari besi kotak berukuran $4 \mathrm{~cm} \mathrm{x} 4 \mathrm{~cm} \mathrm{x} 4 \mathrm{~cm} \times 4 \mathrm{~cm}$ dengan panjang $60 \mathrm{~cm}$.

4. Kerangka alat bantu dibuat dari besi kotak ukuran $4 \mathrm{~cm} \times 4 \mathrm{~cm} \times 4 \mathrm{~cm} \times 4 \mathrm{~cm}$ dengan panjang $200 \mathrm{~cm}$.

Gambar 1. Alat bantu logging pada jalan licin dari rangkaian besi kotak (pandangan atas)

\section{HASIL DAN PEMBAHASAN}

\subsection{Selip pada Jalan Angkutan Kayu}

Rata-rata selip yang terjadi pada penggunaan alat bantu rangkaian besi kotak disajikan pada Tabel 1. 
Tabel 1. Rata-rata selip yang terjadi pada penggunaan alat bantu rangkaian besi kotak

\begin{tabular}{|c|c|c|c|c|c|}
\hline $\begin{array}{c}\text { Lereng } \\
\text { (Slope) } \\
(\%)\end{array}$ & $\begin{array}{l}\text { Muat/kosong } \\
\text { (Load/empty) }\end{array}$ & $\begin{array}{l}\text { Jarak tempuh } \\
5 \text { putaran roda } \\
\text { (mileage of } \\
5 \text { lap wheel) } \\
\text { (m) }\end{array}$ & $\begin{array}{l}\text { Muat/kosong } \\
\text { (Load/empty) }\end{array}$ & $\begin{array}{c}\text { Jarak tempuh } \\
5 \text { putaran roda } \\
\text { (mileage of } \\
5 \text { lap wheel) } \\
\text { (m) }\end{array}$ & $\begin{array}{c}\text { Selip } \\
\text { (Slip) } \\
(\%)\end{array}$ \\
\hline \multirow[t]{2}{*}{8} & $\begin{array}{l}\text { Muat (Load) } \\
\text { Muat (Load) } \\
\text { Muat (Load) } \\
\text { Muat (Load) } \\
\text { Muat (Load) }\end{array}$ & $\begin{array}{c}6,21 \\
9,5 \\
7,12 \\
6,32 \\
8,66\end{array}$ & $\begin{array}{l}\text { Kosong } \\
\text { (Empty) } \\
\text { Kosong } \\
\text { (Empty) } \\
\text { Kosong } \\
\text { (Empty) } \\
\text { Kosong } \\
\text { (Empty) } \\
\text { Kosong } \\
\text { (Empty) }\end{array}$ & $\begin{array}{l}6,39 \\
9,71 \\
7,48 \\
6,52 \\
9,13\end{array}$ & $\begin{array}{l}4,81 \\
3,07 \\
5,15\end{array}$ \\
\hline & $\begin{array}{l}\text { Rata-rata } \\
\text { (Average) }\end{array}$ & 7,56 & & 7,85 & 3,60 \\
\hline \multirow[t]{2}{*}{12} & $\begin{array}{l}\text { Muat (Load) } \\
\text { Muat (Load) } \\
\text { Muat (Load) } \\
\text { Muat (Load) } \\
\text { Muat (Load) }\end{array}$ & $\begin{array}{r}7,69 \\
8,43 \\
9,2 \\
9,56 \\
7,05 \\
\end{array}$ & $\begin{array}{l}\text { Kosong } \\
\text { (Empty) } \\
\text { Kosong } \\
\text { (Empty) } \\
\text { Kosong } \\
\text { (Empty) } \\
\text { Kosong } \\
\text { (Empty) } \\
\text { Kosong } \\
\text { (Empty) }\end{array}$ & $\begin{array}{l}8,16 \\
9,24 \\
9,79 \\
10,32 \\
7,55 \\
\end{array}$ & $\begin{array}{r}5,76 \\
8,77 \\
6,02 \\
7,36 \\
6,62 \\
\end{array}$ \\
\hline & $\begin{array}{l}\text { Rata-rata } \\
\text { (Average) }\end{array}$ & 8,39 & & 9,01 & 6,91 \\
\hline \multirow[t]{2}{*}{18} & $\begin{array}{l}\text { Muat (Load) } \\
\text { Muat (Load) } \\
\text { Muat (Load) } \\
\text { Muat (Load) } \\
\text { Muat (Load) }\end{array}$ & $\begin{array}{l}8,21 \\
8,74 \\
9,28 \\
9,12 \\
8,15 \\
\end{array}$ & $\begin{array}{l}\text { Kosong } \\
\text { (Empty) } \\
\text { Kosong } \\
\text { (Empty) } \\
\text { Kosong } \\
\text { (Empty) } \\
\text { Kosong } \\
\text { (Empty) } \\
\text { Kosong } \\
\text { (Empty) }\end{array}$ & $\begin{array}{l}10,13 \\
10,1 \\
9,14 \\
\end{array}$ & $\begin{array}{l}8,39 \\
9,70 \\
10,83 \\
\end{array}$ \\
\hline & $\begin{array}{l}\text { Rata-rata } \\
\text { (Average) }\end{array}$ & 8,70 & & 9,65 & 9,86 \\
\hline
\end{tabular}

Rata-rata selip yang terjadi pada saat tidak menggunakan alat bantu rangkaian besi kotak disajikan pada Tabel 2. 
Tabel 2. Rata-rata selip yang terjadi pada saat tidak menggunakan alat bantu rangkaian besi kotak

\begin{tabular}{|c|c|c|c|c|c|}
\hline $\begin{array}{c}\text { Lereng } \\
\text { (Slope) } \\
(\%)\end{array}$ & $\begin{array}{l}\text { Muat/kosong } \\
\text { (Load/empty) }\end{array}$ & $\begin{array}{l}\text { Jarak tempuh } \\
5 \text { putaran } \\
\text { roda } \\
\text { (mileage of } \\
5 \text { lap wheel) } \\
\text { (m) }\end{array}$ & $\begin{array}{l}\text { Muat/kosong } \\
\text { (Load/empty) }\end{array}$ & $\begin{array}{l}\text { Jarak tempuh } \\
5 \text { putaran } \\
\text { Roda } \\
\text { (mileage of } \\
5 \text { lap wheel) } \\
\text { (m) }\end{array}$ & $\begin{array}{c}\text { Selip } \\
\text { (Slip) } \\
(\%)\end{array}$ \\
\hline \multirow[t]{2}{*}{8} & $\begin{array}{l}\text { Muat (Load) } \\
\text { Muat (Load) } \\
\text { Muat (Load) } \\
\text { Muat (Load) } \\
\text { Muat (Load) }\end{array}$ & $\begin{array}{l}10,45 \\
10,67 \\
9,73 \\
11,23 \\
11,36 \\
\end{array}$ & $\begin{array}{l}\text { Kosong } \\
\text { (Empty) } \\
\text { Kosong } \\
\text { (Empty) } \\
\text { Kosong } \\
\text { (Empty) } \\
\text { Kosong } \\
\text { (Empty) } \\
\text { Kosong } \\
\text { (Empty) }\end{array}$ & $\begin{array}{l}11,69 \\
11,41 \\
10,86 \\
12,21 \\
12,6 \\
\end{array}$ & $\begin{array}{l}10,60 \\
6,49 \\
10,40 \\
8,03 \\
9,84 \\
\end{array}$ \\
\hline & $\begin{array}{c}\text { Rata-rata } \\
\text { (Average) }\end{array}$ & 10,70 & & 11,75 & 9,07 \\
\hline \multirow[t]{2}{*}{12} & $\begin{array}{l}\text { Muat (Load) } \\
\text { Muat (Load) } \\
\text { Muat (Load) } \\
\text { Muat (Load) } \\
\text { Muat (Load) }\end{array}$ & $\begin{array}{l}11,33 \\
11,17 \\
10,26 \\
10,89 \\
11,29\end{array}$ & $\begin{array}{l}\text { Kosong } \\
\text { (Empty) } \\
\text { Kosong } \\
\text { (Empty) } \\
\text { Kosong } \\
\text { (Empty) } \\
\text { Kosong } \\
\text { (Empty) } \\
\text { Kosong } \\
\text { (Empty) }\end{array}$ & $\begin{array}{l}12,83 \\
12,76 \\
11,44 \\
12,15 \\
12,79\end{array}$ & $\begin{array}{l}11,69 \\
12,46 \\
10,31\end{array}$ \\
\hline & $\begin{array}{l}\text { Rata-rata } \\
\text { (Average) }\end{array}$ & 10,99 & & 12,39 & 11,31 \\
\hline \multirow[t]{2}{*}{18} & $\begin{array}{l}\text { Muat (Load) } \\
\text { Muat (Load) } \\
\text { Muat (Load) } \\
\text { Muat (Load) } \\
\text { Muat (Load) }\end{array}$ & $\begin{array}{l}10,65 \\
11,32 \\
10,68 \\
11,11 \\
10,05\end{array}$ & $\begin{array}{l}\text { Kosong } \\
\text { (Empty) } \\
\text { Kosong } \\
\text { (Empty) } \\
\text { Kosong } \\
\text { (Empty) } \\
\text { Kosong } \\
\text { (Empty) } \\
\text { Kosong } \\
\text { (Empty) }\end{array}$ & $\begin{array}{l}12,31 \\
12,86 \\
12,16\end{array}$ & $\begin{array}{l}13,48 \\
11,98\end{array}$ \\
\hline & $\begin{array}{l}\text { Rata-rata } \\
\text { (Average) }\end{array}$ & 10,76 & & 12,34 & 12,76 \\
\hline
\end{tabular}

Tabel 1 menunjukkan bahwa penggunaan alat bantu rangkaian besi kotak menghasilkan rata-rata selip lebih rendah yaitu 9,86\% daripada tidak menggunakan alat bantu yaitu $12,76 \%$. Terjadi penurunan selip sebesar $12,76 \%-9,86 \%=2,9 \%$. Rendahnya selip pada penggunaan alat bantu 
dikarenakan besi tersebut mencengkram ban truk pada saat supir tidak dapat mengendalikan laju truknya. Saat selip, salah satu roda truk akan terus berputar sedangkan roda yang lain diam di tempat. Supir akan melakukan penginjakan gas secara terus menerus agar roda truk dapat melaju normal. Dengan penggunaan alat bantu, ban truk akan dicengkeram, sehingga ban dapat berputar secara normal dan tidak berputar terus menerus di satu tempat. Dapat dikatakan, penggunaan alat bantu besi kotak yang di rangkai memperbesar traksi truk. Penambahan traksi pada ban truk dapat mengatasi gerakan roda yang berlebihan.

Tekstur tanah pada areal penelitian adalah tanah lempung berliat. Tanah tersebut memiliki sifat apabila basah menjadi licin. Truk akan sangat sulit melintasi tekstur tanah lempung berliat pada saat licin dan basah. Menurut Kalsim dan Sapei (2003) selip roda yang terjadi akan menambah tenaga yang diperlukan untuk penarikan karena gaya horizontal yang diperlukan di atas permukaan tanah lebih besar. Kelunakan atau kelembekan tanah merupakan faktor yang dapat memperbesar deformasi tanah sehingga selip yang terjadi akan semakin besar.

\subsection{Kerusakan Tanah}

Rata-rata kerusakan tanah yang terjadi berupa kedalaman tanah yang terbentuk dengan menggunakan alat bantu rangkaian besi kotak dan tidak menggunakan alat bantu disajikan pada Tabel 3.

Tabel 3. Kerusakan tanah

\begin{tabular}{|c|c|c|c|}
\hline $\begin{array}{c}\text { Kelerengan } \\
\text { (Slope }) \\
(\%)\end{array}$ & $\begin{array}{c}\text { Panjang } \\
\text { petak ukur } \\
\text { (The length } \\
\text { of plot }) \\
(\mathrm{m})\end{array}$ & \multicolumn{2}{|c|}{$\begin{array}{c}\text { Kedalaman tanah } \\
\text { (Depth of soil) } \\
(\mathrm{cm})\end{array}$} \\
\cline { 3 - 4 } & & $\begin{array}{c}\text { Menggunakan } \\
\text { alat bantu } \\
\text { (Using of } \\
\text { auxiliary } \\
\text { tools })\end{array}$ & $\begin{array}{c}\text { Tidak } \\
\text { menggunakan } \\
\text { alat bantu } \\
\text { (Not using of } \\
\text { auxiliary } \\
\text { tools })\end{array}$ \\
\hline 8 & 13 & 1 & 11,4 \\
& & 1,5 & 12,5 \\
& & 1 & 10,7 \\
& & 1,5 & 11,8 \\
& & 2 & 12,2 \\
\hline 12 & Rata-rata & 1,4 & 1,72 \\
\hline & 13 & 2 & 14,7 \\
\hline
\end{tabular}




\begin{tabular}{|c|c|c|c|}
\hline & & 1,5 & 12,9 \\
& & 1,5 & 12,2 \\
& & 1,5 & 11,8 \\
& & 2 & 14,4 \\
\hline \multirow{3}{*}{18} & Rata-rata & 1,7 & 13,2 \\
& (Average) & & \\
& 13 & 2 & 19,4 \\
& & 2 & 20,5 \\
& & 2,5 & 19,7 \\
& & 1,5 & 18,3 \\
& & 2,5 & 19,2 \\
\hline & Rata-rata & 2,1 & 19,42 \\
& (Average) & & \\
\hline
\end{tabular}

Dari Tabel 3 menunjukkan bahwa penggunaan alat bantu rangkaian besi kotak memberikan dampak negatif yang kecil pada kerusakan tanah. Rata-rata kedalaman tanah yang terbentuk dengan menggunakan alat bantu besi kotak pada kelerengan $18 \%$ yaitu $2,1 \mathrm{~cm}$, sedangkan saat tidak menggunakan alat bantu rata-rata kedalaman tanah yang terbentuk yaitu 19,42 cm. Penggunaan alat bantu dapat mengurangi kerusakan tanah saat selip sebesar 89,19\%.

Rendahnya rata-rata kerusakan tanah yang terjadi dengan menggunakan alat bantu rangkaian besi kotak selain karena alat tersebut dapat mencengkeram ban truk sehingga meningkatkan traksi roda, juga bentuk bagian bawah alat yang dirancang dari plat besi yang datar sehingga tidak ada bekas jejak lubang yang ditinggalkan akibat slip oleh ban truk. Gambar dapat dilihat pada lampiran.

Kerusakan tanah yang terjadi tersebut juga dapat menimbulkan kerusakan struktur tanah. Menurut Suprayogo, et al., (2014) Kerusakan struktur tanah diawali dengan penurunan kestabilan agregat tanah, hal tersebut menyebabkan agregat tanah relatif mudah hancur menjadi bentuk halus sehingga membentuk kerak di permukaan tanah (soil crusting) yang memiliki sifat padat dan keras bila kering. Agregat atau partikel tanah yang halus akan terbawa aliran air ke dalam tanah sehingga menyebabkan penyumbatan pori tanah dan pada saat hujan turun kerak yang terbentuk juga menyebabkan penyumbatan pori tanah. Proses penyumbatan pori tanah tersebut mengakibatkan porositas tanah, distribusi pori tanah dan kemampuan tanah untuk mengalirkan air mengalami penurunan dan limpasan permukaan akan meningkat.

Kerusakan tanah akibat selip dapat berakibat pada timbulnya erosi tanah dan peningkatan limpasan permukaan tanah. Hal tersebut sangat berbahaya karena dapat merusak jalan angkutan kayu yang merupakan sarana transportasi untuk mengeluarkan kayu dari dalam hutan. Kelancaran distribusi 
kayu menjadi terhambat. Bagi perusahaan hutan lahan kering, hal tersebut merupakan kerugian bagi mereka baik biaya produksi maupun kelestarian hutan mereka.

Hasil penelitian Yuniawati, et al., (2013) dengan menggunakan alat bantu dari rantai besi ikatan melintang lurus, rata-rata kerusakan tanah yang terjadi sebesar $20,5 \mathrm{~cm}$. Tingginya rata-rata kedalaman tersebut dikarenakan bentuk rantai yang dibuat melintang lurus tidak kuat untuk mencengkeram ban truk saat selip, roda truk masih berputar cepat pada satu tempat sedangkan roda yang lainnya hanya diam tidak bergerak. Akibatnya supir truk berusaha mencari tambahan tenaga/traksi dengan melakukan injakan gas secara terus menerus agar terlepas dari selip. Sedangkan dari hasil penelitian Yuniawati \& Suhartana (2014) menyatakan bahwa dengan kondisi tanah licin dan jalan menurun menghasilkan rata-rata kerusakan tanah lebih tinggi yaitu $24,5 \mathrm{~cm}$ dan $22,9 \mathrm{~cm}$ yang terjadi pada rata-rata selip paling tinggi. Semakin tinggi terjadi selip maka semakin besar kerusakan tanah jalan angkutan kayu yang terjadi.

\subsection{Hubungan Selip dengan Kerusakan Tanah}

Untuk mengetahui hubungan selip ban truk saat menggunakan alat bantu maupun tidak menggunakan alat bantu terhadap kerusakan tanah dilakukan analisis statistik dengan uji t. Analisis menggunakan alat analisis SPSS 18. Hasil analisis disajikan pada Tabel 4.

Tabel 4. Hubungan selip dengan kerusakan tanah

\begin{tabular}{|c|c|c|c|c|c|c|c|c|c|c|}
\hline \multicolumn{11}{|c|}{ Independent Samples Test } \\
\hline & & \multicolumn{2}{|c|}{$\begin{array}{c}\text { Levene's Test } \\
\text { for Equality of } \\
\text { Variances } \\
\end{array}$} & \multicolumn{7}{|c|}{ t-test for Equality of Means } \\
\hline & & \multirow[b]{2}{*}{$\mathrm{F}$} & \multirow[b]{2}{*}{ Sig. } & \multirow[b]{2}{*}{$\mathrm{t}$} & \multirow[b]{2}{*}{ df } & \multirow{2}{*}{$\begin{array}{l}\text { Sig. }(2- \\
\text { tailed) }\end{array}$} & \multirow{2}{*}{$\begin{array}{c}\text { Mean } \\
\text { Difference }\end{array}$} & \multirow{2}{*}{$\begin{array}{l}\text { Std. Error } \\
\text { Difference }\end{array}$} & \multicolumn{2}{|c|}{$\begin{array}{c}95 \% \text { Confidence Interval } \\
\text { of the Difference }\end{array}$} \\
\hline & & & & & & & & & Lower & Upper \\
\hline \multirow[t]{2}{*}{$\begin{array}{l}\text { Kerusakan } \\
\text { _tanah }\end{array}$} & $\begin{array}{l}\text { Equal variances } \\
\text { assumed }\end{array}$ & 43.559 & .000 & -14.047 & 28 & .000 & -13.04667 & .92879 & -14.94921 & -11.14412 \\
\hline & $\begin{array}{l}\text { Equal variances } \\
\text { not assumed }\end{array}$ & & & -14.047 & 14.461 & .000 & -13.04667 & .92879 & -15.03279 & -11.06054 \\
\hline
\end{tabular}

Dari Tabel 4 menunjukkan bahwa nilai probabilitas sebesar 0.000 lebih kecil dari 0,05, maka Ho ditolak artinya kerusakan tanah yang terjadi apabila menggunakan alat bantu lebih rendah daripada tidak menggunakan alat bantu. Melihat hubungan antara selip dengan kerusakan tanah tersebut 
menunjukkan bahwa saat terjadi selip dengan menggunakan alat bantu dapat mengurangi kerusakan tanah.

Kondisi tekstur tanah lempung berliat merupakan salah satu faktor yang memperparah kerusakan tanah. Tekstur tanah tersebut apabila basah akan menjadi licin, saat licin tersebut sering terjadi selip. Tekstur tanah lempung berliat memiliki sifat kembang susut yang tinggi dan jelek pada kondisi air tidak jenuh. Hal tersebut sama dengan hasil penelitian Risman (2008), dimana tanah lempung merupakan tanah yang memiliki kembang susut tinggi dan memiliki daya dukung yang baik pada kondisi tidak jenuh air tetapi jelek pada kondisi jenuh air. Tanah dengan kandungan montmorillonite mempunyai luas permukaan lebih besar dan mudah menyerap air dalam jumlah banyak jika dibandingkan dengan mineral lainnya. Tanah yang memiliki kecepatan terhadap pengaruh air sangat mudah mengembang dan akan cepat merusak struktur yang ada diatasnya.

Menurut Dixon, (1991) dalam Intara, et al., (2011) tanah tekstur liat tidak hanya memiliki permukaan yang luas tetapi juga bermuatan listrik. Muatan listrik tersebut memberi sifat pada liat untuk mengikat air. Hal inilah yang menyebabkan liat banyak menyimpan air. Sifat tanah lempung berliat yang mudah mengembang dan banyak menyimpan air tersebut, mengakibatkan sering terjadinya selip karena kondisi tanah yang licin sehingga rentan terhadap terjadinya kerusakan tanah.

Kerusakan tanah akibat selip juga berakibat pada rusaknya struktur tanah, apabila dibiarkan akan berdampak negatif karena terjadi erosi. Menurut Dariah et al., (2014) tekstur tanah yang halus seperti liat dengan kadar air yang tinggi, maka permeabilitas tanah menjadi sangat lambat, yang berakibat pada pencucian dan pemindahan koloid menjadi terhambat, sehingga terbentuk tanah dengan solum tipis. Apabila hal tersebut terdapat di daerah yang berlereng, karena permeabilitasnya lambat, maka limpasan/aliran permukaan menjadi meningkat, sehingga erosi cukup besar dan terbentuklah tanah bersolum tipis.

Perlakuan jalan tanah angkutan kayu pada tekstur tanah lempung berliat harus lebih diperhatikan, sehingga penggunaan alat bantu untuk mengurangi selip dapat dijadikan pilihan sebagai upaya pencegahan kerusakan tanah.

\section{KESIMPULAN}

Kerusakan tanah yang terjadi saat selip, baik dengan menggunakan alat bantu maupun tidak menggunakan alat bantu menghasilkan beda nyata. Kedalaman tanah sebagai bentuk dari kerusakan 
tanah tersebut, menunjukkan adanya hubungan antara selip dengan kerusakan tanah. Penggunaan alat bantu dapat mengurangi kerusakan tanah sebesar 89,19\%. Kerusakan tanah selain membentuk lubang atau parit juga dapat merusak agregat tanah sehingga dapat menimbulkan erosi. Kerusakan tanah apabila dibiarkan dapat membahayakan supir truk, akibatnya terjadi ketidak lancaran distribusi kayu ke industri pengolahan kayu. Hal tersebut merupakan suatu kerugian bagi perusahaan hutan.

\section{DAFTAR PUSTAKA}

Dariah, A.I., H. Subagyo, C. Tafakresnanto, Setiari dan Marwanto. 2014. Kepekaan tanah terhadap erosi.File://C:/Documents\%20and\%20Settings/user/Favorites/My\%20Documents/berlereng 2.pdf). Diakses pada 12 Maret 2014.

Harseno T, Trimoro A, Sudiro. 2007. Studi hubungan traksi elektronik terhadap kemampuan menahan selip kendaraan bermotor roda 4. Indonesian Science dan Technology. Pusat Dokumentasi dan Informasi Indonesia. Lembaga Ilmu Pengetahuan Indonesia. Bogor.

Intara, Y.I., A. Sapei, Erizal, N. Sembiring, M.H.B. Djoefrie. 2011. Pengaruh pemberian bahan organik pada tanah liat dan lempung berliat terhadap kemampuan mengikat air. Jurnal Ilmu Pertanian Indonesia 16(2):130-135. Institut Pertanian Bogor. Bogor.

Kalsim, D.K, dan A. Sapei. 2003. Fisika lengas tanah. Jurusan Teknik Pertanian. Fakultas Teknik Pertanian. Institut Pertanian Bogor.

Kementerian Kehutanan. 2014. Laporan Hasil Penelitian tahun 2013. Alat bantu logging untuk mengurangi slip pada jalan yang licin. Tidak diterbitkan. Pusat Penelitian dan Pengembangan Keteknikan Kehutanan dan Pengolahan Hasil Hutan. Bogor.

Radite, P.A.S, W. Hermawan, dan A. Soembagijo. 2008. Desain dan pengujian roda besi lahan kering untuk traktor 2-roda. Prosiding Seminar Nasional Teknik Pertanian,Yogyakarta,1819 Nopember 2008. Yogyakarta.

Risman. 2008. Kajian kuat geser dan CBR tanah lepung yang distabilisasi dengan abu terbang dan kapur. Wahana Teknik Sipil 13(2):99-110. Jurusan Teknik Politeknik Negeri Semarang.

Suprayogo, D., Widianto, P. Purnomosidi, R.H. Widodo, F. Rusiana, Z.Z. Aini, N. Khasanah dan Z. Kusuma. 2014. Degradasi sifat fisik tanah sebagai akibat alih guna lahan hutan menjadi sistem kopi monokultur: Kajian perubahan makroporositas tanah. http://www.worldagroforestry.org/sea/publications/files/book/bk0063-04/bk0063-04-8.pdf. di akses 4 Maret 2014. 
Wedhanto, S. 2009. Alat berat dan pemindahan tanah mekanis. Jurusan Teknik Sipil. Universitas Negeri Malang..

Yuniawati, Dulsalam dan Sukadaryati. 2013. Penggunaan rantai sebagai alat bantu mengurangi slip dalam pengangkutan kayu. Jurnal Penelitian Hasil Hutan 31(3):228-234. Pusat Penelitian dan Pengembangan Keteknikan Kehutanan dan Pengolahan Hasil Hutan. Kementrian Kehutanan. Bogor.

Yuniawati, S. Suhartana. 2014. Kerusakan tanah yang terjadi akibat slip pada kegiatan pengangkutan kayu. Jurnal Hutan Tropis 2(1):65-70. Universitas Lambung Mangkurat. Kalimantan Selatan. 


\section{Lampiran Foto}

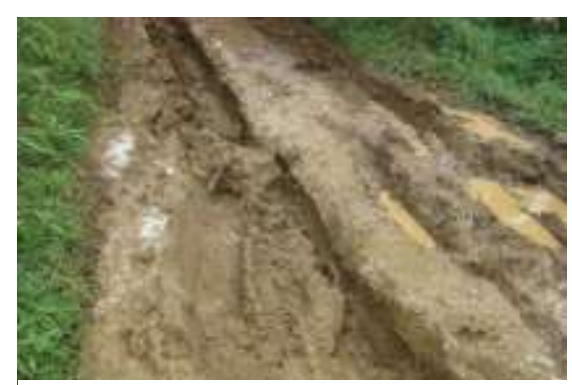

Gbr 1. Kondisi jalan angkutan kayu areal penelitian

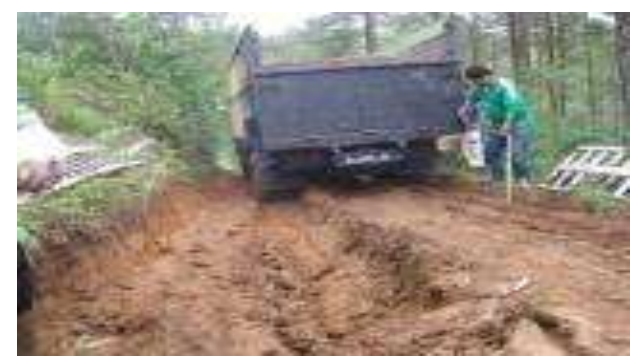

Gbr 3. Kedalaman tanah yang terbentuk saat tidak menggunakan alat bantu

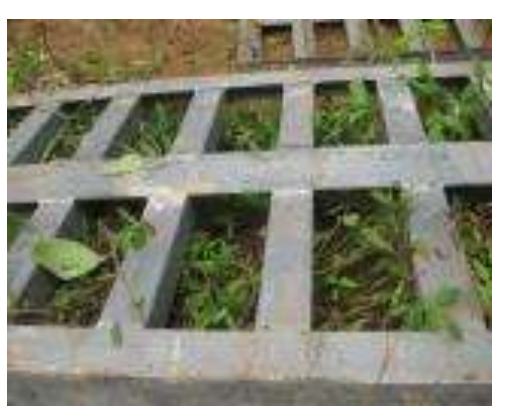

Gbr 2. Alat bantu rangkaian besi kotak

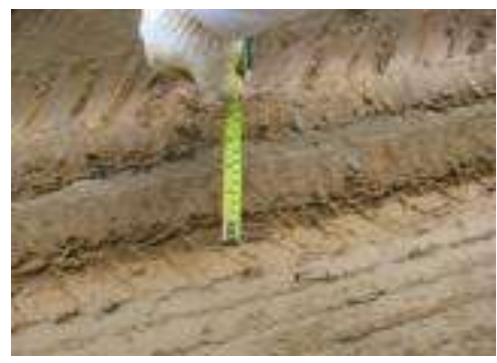

Gbr 4. Kedalaman tanah yang terbentuk dengan menggunakan alat bantu 